\title{
Where Is Your Pain? A Cross-cultural Comparison of the Concept of Pain in Americans and South Koreans
}

\author{
Hyo-eun Kim, ${ }^{a}$ Nina Poth, ${ }^{b}$ Kevin Reuter, ${ }^{c}$ Justin Sytsma ${ }^{d}$ \\ ${ }^{a}$ Hanbat National University, South Korea \\ ${ }^{b}$ Department of Philosophy, Ruhr University Bochum \\ ${ }^{c}$ Institute of Philosophy, University of Bern \\ ${ }^{d}$ Philosophy Programme, Victoria University of Wellington
}

Philosophical orthodoxy holds that pains are mental states, taking this to reflect the ordinary conception of pain. Despite this, evidence is mounting that English speakers do not tend to conceptualize pains in this way; rather, they tend to treat pains as being bodily states. We hypothesize that this is driven by two primary factors-the phenomenology of feeling pains and the surface grammar of pain reports. There is reason to expect that neither of these factors is culturally specific, however, and thus reason to expect that the empirical findings for English speakers will generalize to other cultures and other languages. In this article we begin to test this hypothesis, reporting the results of two cross-cultural studies comparing judgments about the location of referred pains (cases where the felt location of the pain diverges from the bodily damage) between two groups-Americans and South Koreans-that we might otherwise expect to differ in how they understand pains. In line with our predictions, we find that both groups tend to conceive of pains as bodily states.

Keywords: pain, concept of pain, semantics of pain, experimental philosophy, crosscultural study, sound

Pain is a near-universal feature of human life. Almost every person experiences acute pains for shorter or longer periods of time. ${ }^{1}$ Despite pain being essentially universal, there are also notable differences within populations. For example, how intense pains are felt to be and how people respond to

Corresponding author's address: Justin Sytsma, Victoria University of Wellington, Philosophy Programme, Post Office Box 6oo, Wellington 6140, New Zealand. Email: justin.sytsma@vuw.ac.nz.

${ }_{1}^{1}$ Some people are fully insensitive to pain, a phenomenon known as congenital pain insensitivity (Nagasako et al. 2003). 
pains depend on various parameters including both genetic and environmental factors (Nielsen et al. 2009). And during the last few decades, researchers have conducted cross-cultural studies that have revealed the importance of cultural factors for the perception of pain and subsequent pain behavior (Callister 2003; Moore and Brodsgaard 1999; Wierzbicka 2014). Given these results, a further question presents itself: Do people in different cultures conceive of pains differently?

Of particular interest in philosophy has been the question of where people actually locate their pains-hence the title of this paper: Where is your pain? While this question sounds perhaps rather innocent, it has wideranging consequences for the conception of pains. If people think of pains as being located in body parts, then pains are being conceived of as bodily states. In contrast, most philosophical theories of pain take pains to be mental states. ${ }^{2}$ In this paper we will present the results of a pair of cross-cultural studies investigating the location of pains.

Investigating people's concept of pain in a cross-cultural manner is of both theoretical and practical importance. There are several reasons for this. First, the question of whether pains are bodily states or mental states has received considerable attention in the philosophy of mind. ${ }^{3}$ We will argue that cross-cultural studies on people's conception of pain have the potential to significantly advance this debate. Second, within the last five years, researchers have started to empirically investigate the ordinary conception of different mental states, including sensory states like feeling pain (as discussed in the next section). ${ }^{4}$ These studies provide surprising results that cast doubt on assumptions about the ordinary conception of pain found in the philosophical literature. Corroborating these results through crosscultural studies would bolster the position that emerges from these stud-

2 Two clarifications are in order. First, when talking about pains as mental states, we do not intend to endorse any non-physicalist account of the mind. Thus, minds are almost certainly identical or supervenient on physical or functional properties of the brain. Second, brains are, of course, a part of the body. The claim that pains are bodily states should be understood as locating pains in parts of the body outside of the central nervous system.

3 See (Aydede 2009), for an overview of this literature.

${ }^{4}$ Much of this research focuses on how people understand and attribute mental states that philosophers typically treat as being phenomenally conscious. See, for example, (Knobe and Prinz 2008; Sytsma and Machery 2009; Sytsma and Machery 2010; Huebner 2010; Arico et al. 2011; Jack and Robbins 2012; Sytsma 2012; Talbot 2012; Sytsma and Machery 2012; Buckwalter and Phelan 2013; Phelan et al. 2013; Fiala et al. 2014; Sytsma 2014b). For a recent survey, see (Sytsma 2014a). This work falls under the thriving sub-area of experimental philosophy of mind. For an accessible review of some of the work that has been done in this area, see (Machery and Sytsma 2011). For a more extended survey, see (Sytsma 2010b) and the chapter on "Philosophy of Mind" in (Sytsma and Buckwalter 2016). For a collection of cutting-edge articles, see (Sytsma 2014c). 
ies. Third, cross-cultural studies on emotions have revealed that cultural elements influence how people think about and classify emotions (Markus and Kitayama 1991; Mesquita and Ellsworth 2001). The impact of culture on conceptions of pain has received comparatively little attention. Our studies hope to help fill this lacuna. Finally, medical practitioners are increasingly required to provide care and treatment to people from very different cultural backgrounds. It is therefore important to know how and in which ways people's concept of pain depends on the person's cultural background (Free 2002).

Here is how we will proceed. We begin in Section 1 by introducing the philosophical debate that forms the background for our studies and argue that culture is unlikely to significantly affect where people tend to locate pains. In Section 2, we set-up the cross-cultural comparison we make, providing reason to expect that if culture does in fact have a significant effect on where laypeople locate pains, then we should expect to see a notable difference between Americans and South Koreans in this regard. We then present the results of our cross-cultural studies in Section 3 testing our prediction. The implications of these studies are discussed in Section 4.

\section{Pains and places}

In 20 th century analytic philosophy, pains have usually been classified as mental states, and this has been assumed to correspond with the ordinary conception of pain. In fact, awareness of pain has been taken to be the prototypical case of introspective awareness, according to which a person becomes aware of a mental state (Reuter 2016). Moreover, many debates on the mindbody problem have selected pain to be a kind of mental state for which reduction to a brain state seems particularly hard (e.g., Jackson 1980). While these discussions often merely assume the classification of pains as mental states, very few arguments have been put forward to justify this classification.

Most importantly, it has been argued that common sense tells us that pains are like phenomenal mental states and unlike worldly objects in that pains are (i) necessarily private, (ii) subjective, and (iii) cannot be hallucinated (Aydede 2006). Worldly objects like elephants are not exclusive to one person, they do not depend for their existence on being perceived, and they can be dreamed or hallucinated. Hence, they do not fulfill any of the three criteria of phenomenal mental states. In contrast, it has been asserted that pains satisfy all three criteria. First, pains are said to be exclusive to a single person. (Have you ever, non-metaphorically, shared a pain with another person?) Second, it is claimed that the notion of an unfelt, mind-independent 
pain is absurd. ${ }^{5}$ Third, it is held that while people may hallucinate objects like elephants, pains are not the kind of entities that can be hallucinated. ${ }^{6}$ Clearly, you may be uncertain about whether a sensation is truly painful as opposed to merely uncomfortable, for example; but it is asserted that if you feel a pain then you are also undeniably having a pain.

Since (Aydede 2006) and (Hill 2006), the simple picture of the commonsense conception of pain we have just described has come under some scrutiny. Both authors hold that there is a dominant strand in our ordinary conception that takes pains to be mental states; but, they also hold that there is another thread that offers a very different picture. This picture is thought to correspond with the phenomenology of feeling pain and the semantics of pain reports. Starting with the semantics of pain reports, Hill argues that the view that pains are mental states seems to conflict with the way we speak about pains. In standard pain reports, like 'there is a pain in my ankle,' the pains are clearly being located in body parts and not in the mind. Further, the phenomenology of pain, or the way pains feel, seems to support the point drawn from the semantics of pain reports. It is reasonable to suppose that when people locate a pain in a body part, they do so at least in part because that is where the pain is felt to be. When a person says that 'there is a pain in my ankle, this would seem to reflect that she feels a pain as being located in the ankle. Thus, on the one hand, pains appear to be bodily states that are located in a person's body; on the other hand, pains are standardly classified as mental states. This tension has come to be known as the paradox of pain (Aydede 2006; Hill 2006).

Most philosophers have downplayed the relevance of the phenomenology of pain and the semantics of pain reports, or have tried to find alternative explanations of why people speak as if pains have bodily locations (Aydede 2009; Tye 2006). However, in recent years experimental philosophers have begun to investigate whether the commonsense conception of pain indeed supports a view of pains as mental states. The results have not supported the mental state conception of pain advocated by the majority of philosophers and scientists. Instead, the results give us reason to reconsider the importance of the phenomenology of pain and semantics of pain reports in shaping the ordinary conception of pain.

We will briefly review a few of the key findings. Expanding on suggestions about the ordinary conception of colors in (Sytsma 2009), Sytsma (2010a) presented evidence from a series of survey studies challenging the view that pains are necessarily private. In one study, he asked participants to consider a case in which a pair of conjoined twins who share the lower half

5 See (Reuter and Sytsma manuscript) for an extended discussion.

${ }^{6}$ See (Reuter et al. 2014) for an extended discussion. 
of their body, accidentally kick a rock that is hidden in the grass. When the participants were asked whether the twins felt one and the same pain or two different pains, a substantial majority answered that the twins felt one and the same pain.

In other research, Reuter et al. (2014) investigated the claim that the ordinary conception of pain rules out the possibility of pain hallucinations. In stark contrast to the philosophical consensus, a significant majority of the participants surveyed answered that pain hallucinations are possible. Reuter and Sytsma (manuscript) have conducted a large series of studies indicating that a significant majority of English-speakers hold that it is possible to have unfelt pains. They found that a significant majority of participants hold that the pain continues even when the patient isn't feeling it. Employing an indirect method, Reuter (2011) used a web-based corpus analysis to examine the way people express strong and mild pains in English. He found that when pains are strong, people state that they 'have' a pain, whereas mild pains are usually expressed by phrases like 'feeling pain.' This distinction seems to map the appearance-reality distinction that is observed in the traditional sense modalities. If the analogy goes through, it seems as if English speakers distinguish the appearance from the reality of pain, and thus do not regard pains as mental states.

The studies just discussed cast significant doubt on the assumption that the commonsense conception of pain takes pains to be mental states. In doing so, it raises serious doubts about whether there is a paradox of pain in the first place. Recall that the paradox arises because the mental state view is in tension with the phenomenology of feeling pain and the semantics of pain reports, which would seem to be more consistent with a bodily conception of pain. Flipping things around, the phenomenology of feeling pain and the semantics of pain reports would lead us to predict that people would tend to conceive of pains as being bodily states: we would expect that people who grow up feeling pains as being located in body parts, and who are taught to refer to pains as being located in body parts, would be likely to form a bodily conception of pain. And insofar as these two factors are common across human cultures we would expect the bodily conception of pain to be common across human cultures as well.

With regard to the phenomenology of pain, it seems reasonable to suppose that the way people feel their pains is a near-universal facet of human pain perception. While some studies have demonstrated the impact of culture on the felt intensity of pains, no study exists (that we know of) that demonstrates an effect of culture on the felt location of pain. Thus, if bodily damage occurs in a person's elbow, the ensuing pain will be felt to be located

\footnotetext{
7 This finding has also been replicated for German speakers (Reuter et al. manuscript).
} 
in the elbow regardless of whether a person has grown up in a Western society or within an Asian community. A similar argument can be made about the semantics of pain reports. Diller (1980) and others have detailed many differences in the semantics of pain reports between different cultures. However, none of these studies show that the reported location of physical pains changes from one culture to the next.

While the empirical evidence discussed above has focused on the judgments of native English speakers, and predominantly Americans, we do not believe that the two factors supporting the bodily conception of pain are culturally specific. As such, we predict that the types of judgments found in the empirical literature to date will turn out to be culturally robust. Our goal in this paper is to begin to test this prediction by comparing judgments about the location of pain between American and South Korean participants.

In order to investigate the role of the phenomenology of pain as well as the role of the location of the bodily disorder independently of each other, we decided to test people's views on the nature of pain in regards to a phenomenon known as "referred pain." Referred pains are pains that are felt to be located in a place that diverges from the location of the painful stimulus (Arendt-Nielsen and Svensson 2001). We can distinguish three primary positions that one could take with regard to cases of referred pains. First, people might locate the pain where the bodily disorder is, such that the phenomenology plays a sub-ordinate role. Second, people may identify the location of the pain with the felt location regardless of the bodily disorder. Third, people may entertain a mental-state view according to which they locate the pain in the mind instead of in either bodily location. Whatever the outcome, the referred pain case has the advantage of disentangling various aspects of pain that usually co-occur. Thus, an empirical study on people's views on referred pain can provide important insights into the structure of people's concept of pain as well as identifying the factors that influence people's thinking on the nature of pain.

\section{East and West}

Our goal in this paper is to begin to test the prediction that recent empirical findings suggesting against the assumption that ordinary people hold a mental state conception of pain are robust across cultures. In this section we will argue that South Koreans form a suitable comparison case to Americans for purposes of investigating this prediction. First, we note that while the Western tradition has been dominated by Aristotelian and Protestant principles (Schubert and Klein 2011), many East Asian cultures-and specifically South Korea-have a Confucian background (Inglehart and Baker 2000; Varnum et al. 2010). Second, work in cultural psychology indicates that there are 
large, systematic differences in cognitive styles between Westerners and East Asians. Both of these factors might plausibly be predicted to have an influence on the concept of pain. Third, there is an interesting, culture-bound somatization syndrome-Hwa-byung-found only in Korean women. The symptoms of Hwa-byung include emotions, especially anger, being expressed as physical pain in the chest (Park 2004), which is distinguished from major depression and other somatic disorders (Kim et al. 2013). Our goal in this section is not to make specific predictions about what the common conception of pain is amongst South Koreans, but to note that prior to conducting empirical work on the topic one might reasonably expect there to be significant differences between Americans and South Koreans with regard to how they conceptualize pain, including whether they tend to locate pains in the body or in the mind.

\subsection{Individualism versus collectivism}

Members of Western societies, including most American and European countries, usually regard themselves as independent from objects and other people in the world (Hofstede 2011). They tend to have individualist cultures. In contrast, East Asian communities represent collectivist cultures that are oriented towards the Confucian principles of mutual relation and social harmony (Nisbett et al. 2001; Thomas 2005). These differences in Western and East Asian cultures are perhaps most strongly observable when considering people's concept of the self: members of individualist societies generally have an independent self-concept whereas members of collectivist cultures have an interdependent self-concept. ${ }^{8}$ For example, Markus and Kitayama (1991) argue that whereas people from individualist cultures regard themselves as largely autonomous beings, East Asians have an extended sense of social duty.

This focus on the interdependence of oneself with others, as well as the heightened importance of social duty, also manifests itself in a phenomenon known as "face." The basic idea is that being appreciated by one's own social group is an important aspect of the interdependent self-concept (Martinez Mateo et al. 2013; Thomas 2005) that leads individuals to avoid public embarrassment and to maintain a positive social image (Schroll-Machl 2008). Saving face-i.e., maintaining one's social image-is highly associated with both a hierarchical system and a male-dominated family system (Lee et al. 2012). In this social system, people are discouraged from expressing their negative feelings and emo-

${ }^{8}$ A table summarizing the key differences between these different self-conceptions can be found in (Markus and Kitayama 1991, 230). 
tions about the social system..$^{9}$ In South Korea, the suppression of feelings applies particularly strongly to married women (Ketterer et al. 2010). If indeed the expression of one's emotions is taken to destroy harmony within both the family and the society at large, then it is not unreasonable to suppose that many South Koreans will also consider their physical pains to be private, subjective states that have to be coped with on a personal level.

\subsection{Analytic versus holistic styles of thinking}

According to Nisbett et al. (2001) we can distinguish between Western and East Asian cultures in terms of the former tending to show analytic patterns of thought while the latter tends to show holistic patterns of thought. As holistic ideas reflect equality and continuity, they provoke thinking in constellations, relations, and contexts. Thus, East Asian cultures perceive objects as parts of a whole. Western cultures, on the other hand, concentrate on the distinctiveness of objects-often disregarding the context in which they appear-and prefer to provide abstract causal explanations.

These differences in patterns of thought have also been applied to the explanations offered for people's actions (Fiebich and Coltheart 2015). While individuals in Western cultures are more likely to explain other people's behavior by referring to mental states like a person's wishes and opinions, "social identity" explanations play a greater role in East Asian cultures like South Korea. Instead of focusing on an individual's intentions to act in a certain way, East Asians tend to focus on an individual's social role and character. For example, if we imagine a girl, Susi, reaching for a doll, East Asians are more likely to explain this through social identity ('that's what girls do') than reference to mental states ('Susi wants to play with the doll'). Noting the East Asian tendency for taking a holistic view of objects, we might suppose that their conception of pain will tend to be driven by recognition of social norms rather than personal judgment. This is further suggested by the phenomenon of Hwa-byung discussed below.

\subsection{Location of pain and Confucianism: Hwa-byung}

Not only has it been argued that Confucian-bound cultures influence people's conception of self and others, there is also evidence that they directly affect people's handling of states of emotions and pains. This is indicated by an empirical phenomenon called Hwa-byung. The pain-related illness is listed in the Diagnostic and Statistical Manual of Mental Disorders (DSM-IV) as

9 The Korean saying "live three years like being speech-impaired, three years like being hearing impaired, and another three years like being visually impaired" epitomizes the cultural importance of this facet of Korean culture. 
a culture-bound syndrome. Hwa-byung occurs with some frequency in Korean middle-aged women, but not in members of the Japanese or Chinese cultures. $^{10}$

Patients suffering from Hwa-byung, consistently report pain in the upper to middle part of their chest (Lin 1983). However, medically, Hwa-byung is classified as a mental illness with the symptoms being associated with the suppression of emotional distress, especially including anger, resulting from the position of women in society. Scientists assume that this suppression is due to socio-cultural and psychological factors (Park et al. 2012). Since the Confucian idea of social harmony prescribes cooperation as the primary value, Korean women in their middle ages suppress emotion and anger to a much greater extent than has been observed in other societies. As for the psychological side, Park et al. (2012) found that patients indicate a temporary inability to suppress anger, grief, guilt, shame or injury. Given that it is not socially acceptable for women to express their bad feelings and emotions because those are regarded as pushing against family harmony and social stability, Hwa-byung itself can be regarded as an attempt to maintain the Confucian principles underlying the collectivist culture.

Coupled with the principle of keeping one's face, patients have no means to express their emotions and the extent to which they are suffering. And, we suggest, this inability to express states of suffering in South Korea is likely to influence the very idea of suffering-and with it the concept of pain-that South Koreans operate with. In sharp contrast, Americans are allowed, and often encouraged, to express their negative feelings-even when the cause of those feelings is rooted inside the family or society. As such, one might suspect that the concept of pain will differ significantly between the United States and South Korea.

\section{Cross-cultural studies}

We saw in Section 1 that, contra the assumptions of many philosophers, evidence is mounting that the ordinary conception of pain amongst adult Americans does not tend to treat pains as being mental states, but instead tends to locate them in body parts. And we hypothesized that the phenomenology of pain as well as the semantics of pain reports are the two driving factors behind the prevalence of such a bodily conception of pain. In Section 2, we argued that South Koreans are a good test case to investigate whether the findings for English speakers generalize to other cultures and to other languages.

\footnotetext{
${ }^{10}$ Interestingly, while Confucianism originates from China (Xiaohong and Qingyuan 2013), it is currently most pronounced in South Korea.
} 
In this section we describe the results of two new cross-cultural studies that begin to empirically compare the lay conceptions of pain between participants in the United States and South Korea. To do this we assessed people's judgments about a type of case not previously tested in the literaturereferred pains. The case of referred pain is an especially interesting example given our speculation about the factors driving the ordinary conception of pain: while pains are typically felt to be located in the same place as bodily damage, this correlation is broken for cases of referred pain. Thus, while our hypothesis leads us to predict that both Americans and South Koreans will be similar in tending to hold a bodily conception of pain rather than a mental state conception, it does not make a prediction about the relative weight that each group will put on each of these two factors. And, in fact, we might expect that cases of referred pains will be one of the places where cultural differences with regard to the conception of pain will be most pronounced.

For purposes of comparison, we also assessed people's judgments about a case of "referred sound"-a case in which where a sound seems to be coming from diverges from the actual source of the sound. Linguistic practice often seems to treat pains as being located in extra-mental space. The same holds for other sense modalities such as audition. The surface grammar for talk of hearing sounds in English, for example, seems to treat them as perceptual objects located outside of the mind. With regard to pains, however, it has been repeatedly argued (e.g., Aydede 2009) that the surface grammar is misleading when it comes to the ordinary concept of pain, with that concept differing from other sensory concepts like sound in taking pains to be mental states. In contrast, we predict that judgments about sound will be similar to judgments about pain in following the surface grammar.

\subsection{Study 1}

In our first study, participants were given two probes on separate pages. One probe detailed a case of referred pain, while the other detailed a case of referred sound. The order of the two probes was randomly determined. The probes were presented in English to a group of American participants and in Korean to a group of South Korean participants. The English versions of the probes read as follows:

Pain: Jack does not feel well and is brought to the hospital. When the doctor asks him to describe the situation, Jack states that he feels a dull pain in his left arm. The experienced doctor knows immediately that Jack most likely has an infection of one of his internal organs. After running a series of tests, the doctor determines that Jack has a liver infection. The doctor explains to Jack that despite how it feels to him, there is nothing at all wrong with his left arm, and that the real problem is with his liver. 
Which of the following statements do you most agree with?

A. The pain is in Jack's liver and it merely feels to him as if it is in his left arm.

B. The pain is in Jack's left arm, just where he feels it to be.

C. The pain is in Jack's mind, and neither in his left arm nor in his liver.

D. There is no pain-not in Jack's liver, in Jack's left arm, or in Jack's mind.

E. None of the above: I don't agree with any of these statements.

Sound: Jim is walking down the street when it sounds to him as if there is an ambulance siren on his left. When he looks to his left, however, he doesn't see anything. An experienced scientist is sitting on a bench next to Jim and notices his behavior. The scientist knows immediately that the ambulance is probably on Jim's right. After looking around and listening more closely, the scientist determines that the ambulance is in the parking ramp on Jim's right. The scientist explains to Jim that despite how it sounds to him, the siren isn't coming from his left, and that the ambulance is actually on his right.

Which of the following statements do you most agree with?

A. The sound is on Jim's right and it merely sounds to him as if it is on his left.

B. The sound is on Jim's left, just where he hears it to be.

C. The sound is in Jim's mind, and neither on his left nor his right.

D. There is no sound-not on Jim's right, on Jim's left, or in Jim's mind.

E. None of the above: I don't agree with any of these statements. ${ }^{11}$

The first two options give the pain/sound a physical location (either where the source of the pain/sound is or where the pain/sound seems to be), while the third gives it a mental location. After answering each question, the American participants were asked to briefly explain their answer.

Responses were collected online and restricted to participants who were 18 years of age or older, who completed the survey, had not taken a survey through the website previously, and had at most minimal training in philosophy. ${ }^{12}$ Responses for the English version of the probes were restricted

${ }^{11}$ The Korean translations of the probes are given in the appendix.

${ }^{12}$ Responses for the English version of the probes were collected through http://www.philosophicalpersonality.com while responses for the Korean version of the probes were collected through Qualtrics (http://www.qualtrics.com). Participants were counted as having more than minimal training in philosophy for the American sample if they were philosophy majors, had completed a degree with a major in philosophy, or had taken graduate-level courses in philosophy; participants were counted as having more than minimal training in philosophy for the South Korean sample if they had graduated or were going to graduate with an undergraduate degree in philosophy. 
to participants born and currently residing in the United States, while responses for the Korean version of the probes were restricted to South Koreans. We collected responses from 190 Americans and from 196 South Koreans. ${ }^{13}$ The results are shown in Figure 1.
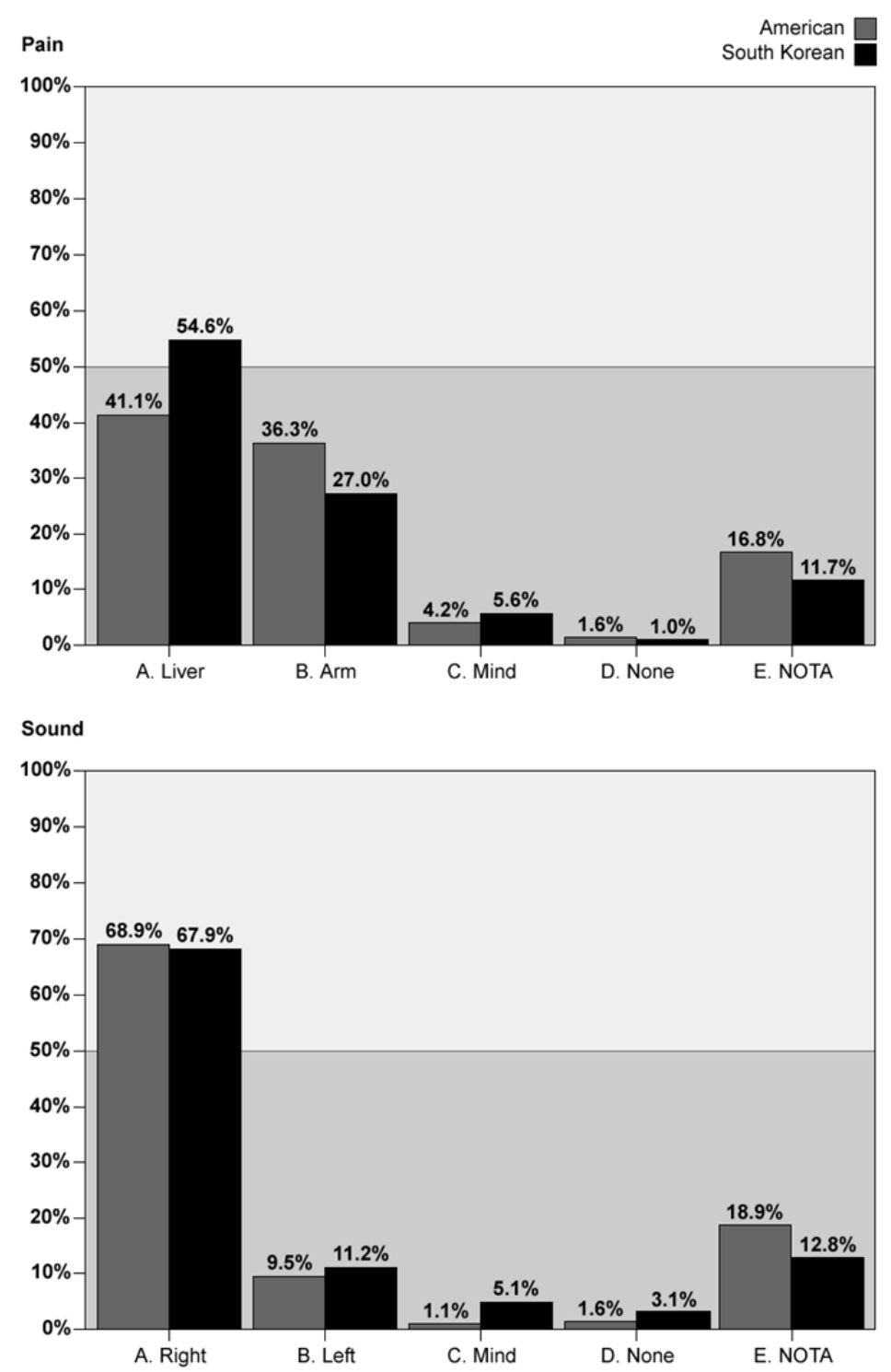

Fig. 1. Results of Study 1 in terms of percentage of participants from each group selecting each answer choice; pain case on top, sound case on bottom.

${ }^{13}$ The American participants were $71.6 \%$ women, with an average age of 40.9 years; the South Korean participants were $64.3 \%$ women, with an average age of 30.0 . 


\subsubsection{Pain}

We will begin by looking at the results for the pain probes. We predicted that (1) the American participants would tend to locate the pain in a body part and not in the mind, (2) the South Korean participants would also tend to locate the pain in a body part and not in the mind, and (3) that the two groups would be similar in this regard. The data support each of these three predictions.

First, we found that a significant majority of the American participants located the pain in Jack's body by selecting one of the first two options (77.4\%); in contrast, only a small minority located the pain in Jack's mind (4.2\%). ${ }^{14}$ Second, as with the Americans, we found that a significant majority of the South Korean participants located the pain in Jack's body (81.6\%); in contrast, only a small minority located the pain in Jack's mind (5.6\%). ${ }^{15}$ Third, it follows from the previous two findings that the American and South Korean participants were similar with regard to locating the pain in a body part and not in the mind. Further, we found no significant differences either when comparing the percentage of participants in each group selecting Options A or B (physical locations), or the percentage of participants in each group selecting Option C (mental location). ${ }^{16}$

As noted above, our hypothesis did not lead us to make a prediction about the relative preference that Americans and South Koreans might have for either of the two bodily locations for pain. That said, it is worth noting that our data suggests that there might be a small cultural difference here: South Koreans were significantly more likely than Americans to select Option A (a difference of 13.5 percentage points), while Americans were more likely than South Koreans to select Option B (a difference of 9.3 percentage points; this difference was borderline significant). ${ }^{17}$ Further, while only slightly more of the American participants selected Option A than selected

${ }^{14}$ Option A or B: $\chi 2=55.8368, p=3.937 e-14$, one-tailed (Cohen's $h=0.5792$, where a value of 0.5 is ordinarily classified as a medium effect and a value of 0.8 is ordinarily classified as a large effect); Option C: $\chi^{2}=157.5211, p<2.2 e-16$, one-tailed (Cohen's $h=1.157$, where a value of 0.8 or above is ordinarily classified as a large effect).

${ }^{15}$ Option A or B: $\chi_{2}=77.1888, p<2.2 e-16$, one-tailed (Cohen's $h=0.685$, where a value of 0.5 is ordinarily classified as a medium effect and a value of 0.8 is ordinarily classified as a large effect); Option C: $\chi^{2}=152.699, p<2.2 e-16$, one-tailed (Cohen's $h=1.092$, where a value of 0.8 or above is ordinarily classified as a large effect).

${ }^{16}$ Option A or B: $\chi^{2}=0.8317, p=0.3618$, two-tailed; Option C: $\chi^{2}=0.1609, p=0.6883$, two-tailed. With sample sizes of 190 and 196, for each comparison we had a power of 0.9984 to detect a medium-sized effect (Cohen's $h=0.5$ ).

${ }^{17}$ Option A: $\chi^{2}=6.5541, p=0.01046$, two-tailed (Cohen's $h=0.2719$, where a value of 0.2 is ordinarily classified as a small effect and a value of 0.5 is ordinarily classified as a medium effect); Option B: $\chi^{2}=3.4223, p=0.06432$, two-tailed (Cohen's $h=0.1999$, where a value of 0.2 or below is ordinarily classified as a small effect). 
Option B, more than twice as many of the South Korean participants selected Option A than selected Option B. Thus, while both groups showed a slight preference for locating the pain in the liver compared to the arm, this preference was much stronger amongst the South Korean participants. In fact, if we look at those participants who selected one of the two physical locations, we find a significant difference between the responses of the Americans and the South Koreans. ${ }^{18}$

\subsubsection{Sound}

While our focus in this article is on the ordinary conception of pain, we also asked participants about a case of "referred sound." The two factors that led us to predict that Americans and South Koreans would be similar in treating pains as physical rather than mental hold for other sensory modalities as well. As such, the referred sound probes serve as an additional test. Corresponding with our predictions for the previous case, we predicted that (1) the American participants would tend to locate the sound in the world and not in the mind, (2) the South Korean participants would also tend to locate the sound in the world and not in the mind, and (3) that the two groups would be similar in this regard. Once again, the data support each of these three predictions.

First, we found that a significant majority of the American participants located the sound in Jim's surroundings by selecting one of the first two options (78.4\%); in contrast, only a small minority located the sound in Jim's mind $(1.1 \%) .{ }^{19}$ Second, as with the Americans, we found that a significant majority of the South Korean participants located the sound in Jim's surroundings (79.1\%); in contrast, only a small minority located the sound in Jim's mind (5.1\%). ${ }^{20}$ Third, it follows from the previous two findings that the

${ }^{18} \chi_{2}=5.5415, p=0.01857$, two-tailed (Cohen's $h=0.283$, where a value of 0.2 is ordinarily classified as a small effect and a value of 0.5 is ordinarily classified as a medium effect). If we instead look at all of the participants, the difference between the responses of the two groups is only borderline significant: $\chi 2=8.6996, p=0.06906$ (Cramer's $V=0.1501256$, where a value of 0.1 is ordinarily classified as a small effect and a value of 0.3 is ordinary classified as a medium effect). It might be noted that the number of participants selecting Option D for each sample is worryingly small, but a Fisher's exact test yields a similar result $(p=0.06122)$.

${ }^{19}$ Option A or B: $\chi^{2}=60.2579, p=4.16 e-15$, one-tailed (Cohen's $h=0.6046$, where a value of 0.5 is ordinarily classified as a medium effect and a value of 0.8 is ordinarily classified as a large effect); Option C: $\chi^{2}=180.1316, p<2.2 e-16$, one-tailed (Cohen's $h=1.365$, where a value of 0.8 or above is ordinarily classified as a large effect).

${ }^{20}$ Option A or B: $\chi 2=65.148, p=3.474 e-16$, one-tailed (Cohen's $h=0.6207$, where a value of 0.5 is ordinarily classified as a medium effect and a value of 0.8 is ordinarily classified as a large effect); Option C: $\chi 2=156.25, p<2.2 e-16$, one-tailed (Cohen's $h=1.115$, where a value of 0.8 or above is ordinarily classified as a large effect). 
American and South Korean participants were similar with regard to locating the sound in Jim's surroundings and not in his mind. Further, we found no significant differences when comparing the percentage of participants in each group selecting Options A or B (physical locations); we did, however, find a significant difference between the percentage of participants in each group selecting Option C (mental location), although the percentages were small in each case $(5.1 \%$ vs. $1.1 \%){ }^{21}$

Again, our hypothesis did not lead us to make a prediction about the relative preference that Americans and South Koreans might have for either of the two physical locations for sound. That said, it is worth noting that our data does not give us reason to suppose that there is a large difference between the two groups in this regard, as we found no significant differences between the percentage of participants in each group selecting Option A or between the percentage of participants in each group selecting Option $\mathrm{B}^{22}$ Further, if we look at those participants who selected one of the two physical locations, we do not find a significant difference between the responses of the Americans and the South Koreans. ${ }^{23}$ We did find that each group showed a strong preference for locating the sound on Jim's right (where the source of the sound is) rather than on Jim's left (where the sound seemed to be), however, with the American participants being over seven times more likely to select Option A than Option B and the South Korean participants being over six times more likely to select Option A than Option B. This difference was much more pronounced than it was for the pain probe and warrants further investigation.

\subsection{Study 2}

It might be worried that participants in our first study did not have strong opinions about the questions, but that the multiple-choice format nonetheless forced them to select an answer. While there are reasons to doubt that

${ }^{21}$ Option A or B: $\chi 2=0.0012, p=0.9727$, two-tailed. With sample sizes of 190 and 196 , we had a power of 0.9984 to detect a medium-sized effect (Cohen's $h=0.5$ ). Option C: $\chi_{2}=3.9937, p=0.04567$, two-tailed (Cohen's $h=0.2501$, where a value of 0.2 is ordinarily classified as a small effect and a value of 0.5 is ordinarily classified as a medium effect).

${ }^{22}$ Option A: $\chi_{2}^{2}=0.0146, p=0.9038$, two-tailed; Option B: $\chi^{2}=0.1578, p=0.6912$, twotailed. Again, with sample sizes of 190 and 196, for each comparison we had a power of 0.9984 to detect a medium-sized effect (Cohen's $h=0.5$ ).

${ }^{23} \chi^{2}=0.1407, p=0.7076$. With sample sizes of 155 and 149 , we had a power of 0.9918 to detect a medium-sized effect (Cohen's $h=0.5$ ). If we instead look at all of the participants, the difference between the responses of the two groups is only borderline significant: $\chi^{2}=$ 8.6409, $p=0.07073$ (Cramer's $V=0.1496$, where a value of 0.1 is ordinarily classified as a small effect and a value of 0.3 is ordinary classified as a medium effect). It might be noted that the number of participants selecting Options $C$ and D for the American sample is worryingly small, but a Fisher's exact test yields a similar result $(p=0.06796)$. 
this would dramatically skew our results (see Sytsma and Livengood 2016, Chapter 9, for discussion), our second study removed this worry by changing the question format to allow for a neutral response to each option.

Participants were given one of the two vignettes described above-either the referred pain or the referred sound vignette-then asked how strongly they agreed or disagreed with each of four claims using a 7-point scale anchored at 1 with "Strongly Disagree," at 4 with "Neutral," and at 7 with "Strongly Agree." The claims for the English version of the pain probe were:

1. The pain is in Jack's liver and it merely feels to him as if it is in his left arm.

2. The pain is in Jack's left arm, just where he feels it to be.

3. The pain is in Jack's mind, and neither in his left arm nor in his liver.

4. There is no pain-not in Jack's liver, in Jack's left arm, or in Jack's mind.

The first two claims give the pain a physical location (either where the damage is or where the pain if felt to be), while the third claim gives it a mental location and the fourth claim captures skepticism about the pain. The claims for the sound probe followed the same schematic. ${ }^{24}$ Responses were collected using the same websites and restrictions as the previous study. We collected responses from 247 Americans (93 for the pain probe, 154 for the sound probe) and from 188 South Koreans ( 93 for the pain probe, 95 for the sound probe). ${ }^{25}$

In addition to participants' responses to each of the four individual claims we asked them about, we were interested in how their responses to the first two claims (assigning one of two physical locations to the pain or sound) compared with their responses to the third claim (assigning a mental location to the pain or sound). To test this we calculated the highest response that each person gave to either Claim 1 or Claim 2 (MAX). We were also interested in determining whether participants endorsed one or the other of

${ }^{24}$ The English version of the sound claims: 1 . The sound is on Jim's right and it merely sounds to him as if it is on his left.

2. The sound is on Jim's left, just where he hears it to be.

3. The sound is in Jim's mind, and neither on his left nor his right.

4. There is no sound-not on Jim's right, on Jim's left, or in Jim's mind.

The Korean translations of the claims for the pain probe and the sound probe are included in the appendix.

${ }^{25}$ The American participants were $55.1 \%$ women, with an average age of 32.2 years; the South Korean participants were $71.3 \%$ women, with an average age of 29.6 . 
these two claims and whether they endorsed the third claim, where a participant was counted as endorsing a claim if she selected either 5,6 , or 7 for it on the 7-point scale. As such, we calculated the percentage endorsing either Claim 1 or Claim 2 (PHYSICAL) and the percentage endorsing Claim 3 (MENTAL). The results-including MAX, PHYSICAL, and MENTAL-are shown in Figure 2.
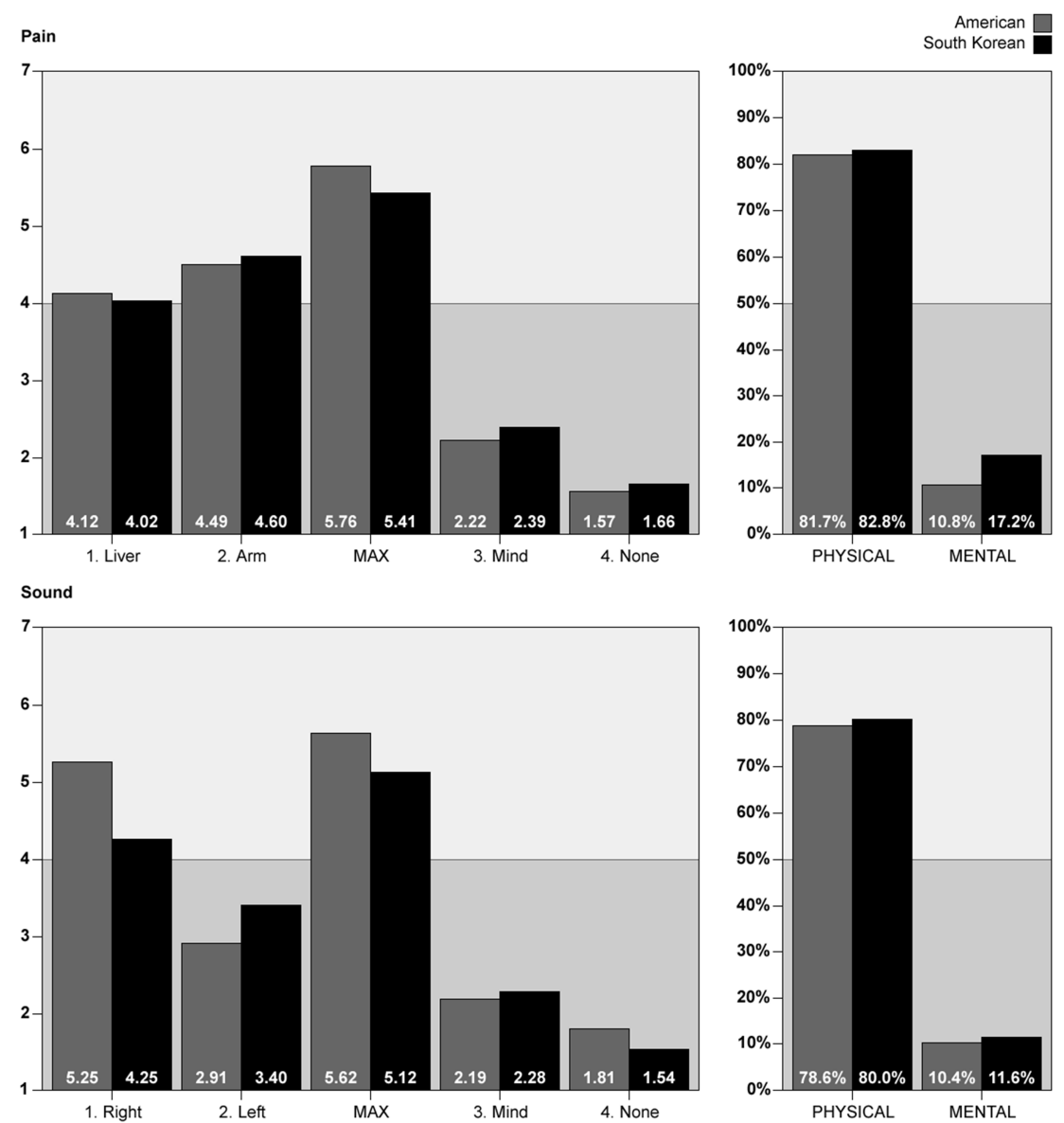

Fig. 2. Results of Study 2 with mean response on left and percent endorsing on right; pain case on top, sound case on bottom.

\subsubsection{Pain}

We will begin by looking at the results for the pain probes. Recall our three predictions: (1) that the American participants would tend to locate the pain in a body part and not in the mind, (2) that the South Korean participants would also tend to locate the pain in a body part and not in the mind, and 
(3) that the two groups would be similar in this regard. Once again the data support each of our three predictions.

First, we found that the American participants tended to give low answers to the claim that the pain was in Jack's mind (Claim 3), with the mean response for this claim (2.22) being significantly below the neutral point. ${ }^{26}$ Further, Americans tended to give high answers to at least one of the two claims locating the pain in Jack's body-either his liver (Claim 1) or his arm (Claim 2) - with the mean response for MAX (5.76) being significantly above the neutral point. ${ }^{27}$ In addition, we found that a significant majority endorsed one of the first two claims $(81.7 \%)$, while only a minority endorsed the third claim (10.8\%). ${ }^{28}$ Finally, it is worth noting that the American participants tended to treat the pain as either being located in the body or as being located in the mind, with only one participant out of 93 (1.1\%) failing to endorse one of the first three claims and only eight participants $(8.6 \%)$ endorsing both one of the first two claims and the third claim.

Second, as with the Americans, we found that the South Korean participants tended to give low answers to the claim that the pain was in Jack's mind (Claim 3), with the mean response for this claim (2.39) being significantly below the neutral point. ${ }^{29}$ Further, South Koreans also tended to give high answers to at least one of the two claims locating the pain in Jack's body with the mean response for MAX (5.41) being significantly above the neutral point. ${ }^{30}$ And we again found that a significant majority endorsed one of the first two claims $(82.8 \%)$, while only a minority endorsed the third claim $(17.2 \%) .{ }^{31}$ Finally, it is worth noting that like the Americans the South Korean participants tended to treat the pain as either being located in the body or as being located in the mind, with only five participants out of 93 (5.4\%) fail-

${ }^{26} t=-10.5332, p<2.2 e-16$, one-tailed (Cohen's $d=1.092$, where a value of 0.8 or above is ordinarily classified as a large effect).

${ }^{27} t=14.0494, p<2.2 e-16$, one-tailed (Cohen's $d=1.457$, where a value of 0.8 or above is ordinarily classified as a large effect).

${ }^{28}$ PHYSICAL: $\chi_{2}=36.172, p=9.032 e-10$, one-tailed (Cohen's $h=0.6872$, where a value of 0.5 is ordinarily classified as a medium effect and a value of 0.8 is ordinarily classified as a large effect); MENTAL: $\chi^{2}=55.7419, p=4.132 e-14$, one-tailed (Cohen's $h=0.9026$, where a value of 0.8 or above is ordinarily classified as a large effect).

${ }^{29} t=-9.3233, p=3.029 e-15$, one-tailed (Cohen's $d=0.9668$, where a value of 0.8 or above is ordinarily classified as a large effect).

${ }^{30} t=9.8081, p=2.892 e-16$, one-tailed (Cohen's $d=1.017$, where a value of 0.8 or above is ordinarily classified as a large effect).

${ }^{31}$ PHYSICAL: $\chi 2=38.7097, p=2.459 e-10$, one-tailed (Cohen's $h=0.7154$, where a value of 0.5 is ordinarily classified as a medium effect and a value of 0.8 is ordinarily classified as a large effect); MENTAL: $\chi^{2}=38.7097, p=2.459 e-10$, one-tailed (Cohen's $h=0.7154$, where a value of 0.5 is ordinarily classified as a medium effect and a value of 0.8 is ordinarily classified as a large effect). 
ing to endorse one of the first three claims and only 13 participants (14.0\%) endorsing both one of the first two claims and the third claim.

Third, it follows from what we have just reported that the American and South Korean participants were similar with regard to locating the pain in a body part and not in the mind. Further, directly comparing the responses of the two groups for Claim 3 reveals no significant difference. ${ }^{32}$ Likewise, there was no significant difference between the percentage of Americans and the percentage of South Koreans endorsing at least one of the first two claims, and there was no significant difference between the percentage of Americans and the percentage of South Koreans endorsing the third claim. ${ }^{33}$

Recall that while our hypothesis did not lead us to make a prediction about the relative preference that Americans and South Koreans might have for either of the two bodily locations for pain, the results of our first study suggested that there might be a small cultural difference in this regard. Based on this finding, we predicted that we would find similar differences in our second study between the mean responses of the American and South Korean participants to Claim 1 (liver) and the mean responses to Claim 2 (arm). These predictions were not born out by the data, however: we found no significant differences between responses for either Claim 1 or Claim 2. ${ }^{34}$ Further, we found no significant difference between the responses of the two groups across Claims 1 and 2, or between their responses across all four claims. ${ }^{35}$ This might not be telling the whole story, however, as suggested by the scatterplots of responses to the first two questions (spreading out the responses when multiple participants gave the same pattern) shown in Figure 3. In keeping with results of our first study, we see that more responses fell into the upper left quadrant than the lower right quadrant for each group, indicating that more participants endorsed the claim that the pain was in the liver while denying the claim that the pain was in the arm (26.9\% US, $33.3 \%$ South Korea) than showed the reverse pattern (24.7\% US, $15.1 \%$ South Korea). Further, this preference was again much stronger amongst the South Korean participants than the American participants. ${ }^{36}$

${ }^{32} t=0.7104, p=0.4783$, two-tailed. With sample sizes of 93 and 93 we had a power of 0.9239 to detect a medium-sized effect (Cohen's $d=0.5$ ).

${ }^{33}$ PHYSICAL: $\chi^{2}=0, p=1$, two-tailed; MENTAL: $\chi^{2}=1.1178, p=0.2904$, two-tailed. With sample sizes of 93 and 93, for each comparison we had a power of 0.9264 to detect a medium-sized effect (Cohen's $h=0.5$ ).

${ }^{34}$ Claim 1: $t=0.3337, p=0.3695$, one-tailed; Claim 2: $t=-0.3832, p=0.351$, one-tailed. With sample sizes of 93 and 93, for each comparison we had a power of 0.9601 to detect a medium-sized effect (Cohen's $d=0.5$ ).

${ }^{35}$ Claims 1 and 2: Pillai's trace $=0.00104, F(2,183)=0.09521, p=0.9092$. Claims 1-4: Pillai's trace $=0.004359, F(4,181)=0.198, p=0.9391$.

${ }^{36}$ Classifying participants as either endorsing a claim (selecting 5,6 , or 7 ), denying a claim (selecting 1,2, or 3), or neutral (selecting 4), we found a significant difference between 

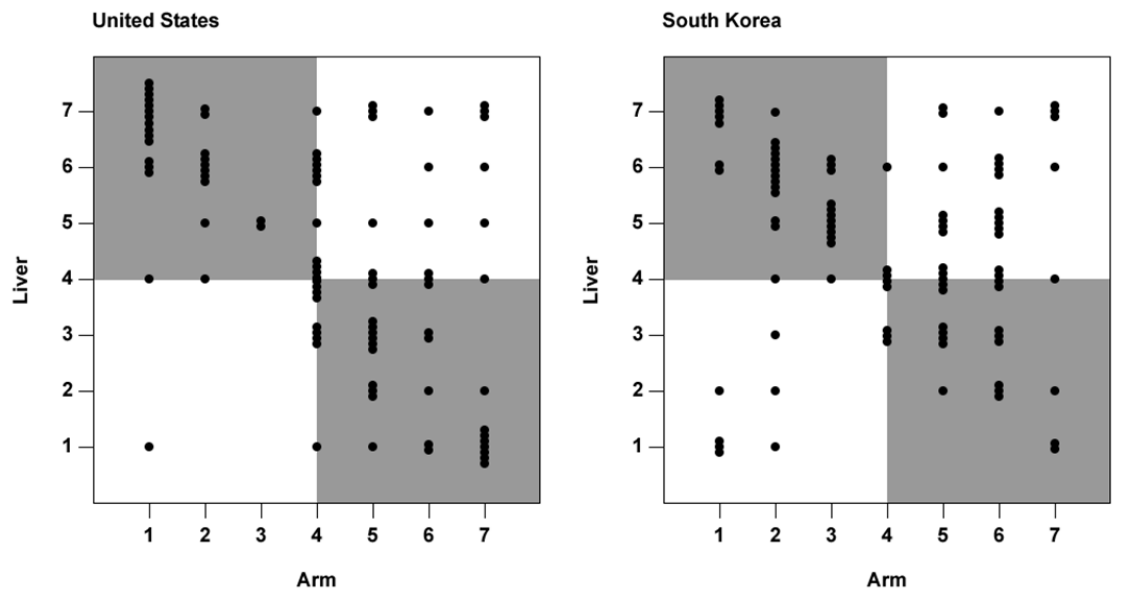

Fig. 3. Scatterplots for responses to Question 1 (y-axis) and Question 2 (x-axis) for Study 2, spreading out the responses when multiple participants fell on the same point.

\subsubsection{Sound}

The results of our second study also supported each of our three predictions with regard to the referred sound case. (1) We found that the American participants tended to give low answers to Claim 3 (2.19), with only a small minority endorsing this claim (10.4\%), and high answers to either Claim 1 or Claim 2 (5.62), with a significant majority (78.6\%) endorsing at least one of these claims. ${ }^{37}(2)$ The South Korean participants tended to give low answers to Claim 3 (2.28), with only a small minority endorsing this claim (11.6\%),

the pattern of responses to Claims 1 and 2 given by Americans and by South Koreans. Distinguishing between those participants who denied both claims (lower left quadrants in Figure 3), those who endorsed both claims (upper right quadrants), those who endorsed Claim 1 and denied Claim 2 (upper left quadrants), those who denied Claim 2 and endorsed Claim 1 (lower right quadrants), and those who were neutral with regard to one or the other of the claims (falling on the dividing lines between quadrants), we get $\chi_{2}=12.556$, $p=0.01366$ (Cramer's $V=0.2598$, where a value of 0.1 is ordinarily classified as a small effect and a value of 0.3 is ordinary classified as a medium effect). It might be noted that the number of participants falling into the lower left quadrant for the American sample is worryingly small, but a Fisher's exact test yields a similar result $(p=0.01329)$.

${ }^{37}$ Claim 3: $t=-12.8065, p<2.2 e-16$, one-tailed (Cohen's $d=1.032$, where a value of 0.8 or above is ordinarily classified as a large effect); MENTAL: $\chi^{2}=95.0714, p<2.2 e-16$, one-tailed (Cohen's $h=0.9144$, where a value of 0.8 or above is ordinarily classified as a large effect); MAX: $t=14.8749, p<2.2 e-16$ (Cohen's $d=1.197$, where a value of 0.8 or above is ordinarily classified as a large effect); PHYSICAL: $\chi^{2}=49.1494, p=1.186 e-12$ 
and high answers to either Claim 1 or Claim 2 (5.12), with a significant majority $(80.0 \%)$ endorsing at least one of these claims. ${ }^{38}$ (3) We found no significant difference between the responses of the American and the South Korean participants for Claim 3, between the percentages endorsing this claim, or between the percentages endorsing either Claim 1 or Claim 2. ${ }^{39}$

Recall that while our hypothesis did not lead us to make a prediction about the relative preference that Americans and South Koreans might have for either of the two physical locations for sound, our first study found no significant differences between the two groups in this regard. Based on this finding, we did not expect to find significant differences between the mean responses to Claim 1 (right) and the mean responses to Claim 2 (left) between the American and South Korean participants in our second study. Against our expectations, we found significant differences between the responses for both Claim 1 and Claim 2, with the American participants showing a stronger preference than the South Korean participants for locating the sound where the source is rather than where it seems to be. ${ }^{40}$ This finding is worthy of further study. Finally, we again found that each group was significantly more likely to locate the sound on Jim's right (where the source of the sound is) than on Jim's left (where the sound seemed to be), although this preference was not as pronounced as in the first study. ${ }^{41}$

(Cohen's $h=0.6082$, where a value of 0.5 is ordinarily classified as a medium effect and a value of 0.8 is ordinarily classified as a large effect).

${ }^{38}$ Claim 3: $t=-10.3099, p<2.2 e-16$, one-tailed (Cohen's $d=1.058$, where a value of 0.8 or above is ordinarily classified as a large effect); MENTAL: $\chi 2=54.5684, p=7.506 e-14$, one-tailed (Cohen's $h=0.8764$, where a value of 0.8 or above is ordinarily classified as a large effect); MAX: $t=7.615, p=1.017 e-11$ (Cohen's $d=0.7813$, where a value of 0.5 is ordinarily classified as a medium effect and a value of 0.8 is ordinarily classified as a large effect); PHYSICAL: $\chi^{2}=33.0105, p=4.583 e-09$ (Cohen's $h=0.6435$, where a value of 0.5 is ordinarily classified as a medium effect and a value of 0.8 is ordinarily classified as a large effect).

${ }^{39}$ Claim 3: $t=0.4391, p=0.6611$ (with sample sizes of 154 and 95 we had a power of 0.9684 to detect a medium-sized effect (Cohen's $d=0.5$ )); MENTAL: $\chi^{2}=0.007, p=0.9335$ (with sample sizes of 154 and 95 we had a power of 0.9694 to detect a medium-sized effect (Cohen's $d=0.5$ )); PHYSICAL: $\chi^{2}=0.0119, p=0.9133$ (again, with sample sizes of 154 and 95 we had a power of 0.9694 to detect a medium-sized effect (Cohen's $d=0.5)$ ).

${ }^{40}$ Claim 1: $t=-4.298, p=2.729 e-05$, two-tailed (Cohen's $d=0.5658$, where a value of 0.5 is ordinarily classified as a medium effect and a value of 0.8 is ordinarily classified as a large effect); Claim 2: $t=2.0893, p=0.03797$, two-tailed (Cohen's $d=0.2732$, where a value of 0.2 is ordinarily classified as a small effect and a value of 0.5 is ordinarily classified as a medium effect).

${ }^{41}$ Americans: $t=9.5749, p<2.2 e-16$, one-tailed (Cohen's $d=1.334$, where a value of 0.8 or above is ordinarily classified as a large effect); South Koreans: $t=2.7768, p=0.003313$, one-tailed (Cohen's $d=0.4715$, where a value of 0.2 is ordinarily classified as a small effect and a value of 0.5 is ordinarily classified as a medium effect). 


\section{Discussion}

Previous empirical studies have indicated that a majority of English speakers think differently about the nature of pain than philosophers typically claim. These studies suggest that instead of conceiving of pains as mental states, they conceive of them as bodily states. As such, while we agree with Aydede (2006) and Hill (2006) that both the phenomenology of feeling pain and the surface grammar of our pain reports indicate a bodily conception of pain, we disagree with their assertion that this represents a recessive strand in people's thinking about pain. Instead we hold that the ordinary conception of pains treats them as bodily states, and we hold that this conception is driven by the two factors that Aydede and Hill note.

In this paper, we directly investigated our proposal by asking three questions:

1. Would an empirical study confirm previous results that people think of pains as bodily states even if the felt location of pain is dissociated from the bodily disorder in a person's body?

2. Do cultural differences between Americans and South Koreans influence people's thinking about the location of pain, challenging the importance of the phenomenology of feeling pain and the surface grammar of pain reports?

3. Are the response profiles regarding the location of pains and sounds similar, indicating that people consider both pains and sounds to be perceptible objects?

The data that we presented in Section 3 strongly suggest a positive answer to the first and third question and a negative answer to the second one. In this section we will consider each of these three questions, discussing our results and looking at possible objections.

\subsection{The bodily conception of pain confirmed}

The referred pain scenario was chosen because it questions whether and how much the phenomenology of feeling pain as well as the semantics of pain reports play a role in our thinking about the nature of pain. In most painful situations, we feel pain where a bodily disorder has occurred. The referred pain case dissociates the phenomenology of feeling pain from the bodily disorder. Furthermore, we usually report the location of a pain to be where we presume the bodily disorder is located. Again, the referred pain case provides a violation of this statistical norm. Of course, if people hold that pains are mental states-as the philosophical orthodoxy asserts-then these dissociations should be of no concern: if pains are mental states that are caused 
by bodily disorders, then a given pain might incorrectly represent the location of the disorder. In contrast, if people hold a bodily conception of pain, then the location of pain may either follow the felt location or, alternatively, may be identified with the location of the bodily disorder.

The results of our studies show that people reject the view that pains are mental states. In each study, a large majority answered that the pain was in one of the bodily locations, while only a small minority answered that it was located in the mind. Thus, this investigation confirms previous studies in suggesting a dominant bodily conception of pain. Our studies, however, diverged from many previous studies in explicitly asking people about the location of pain rather than inquiring about the possibility of shared pains, unfelt pains, or pain hallucinations. ${ }^{42}$

Some people might find the methodology of asking participants directly about the location of a pain to be problematic, however. This objection can be specified in two primary ways, neither of which we find convincing. First, it might be argued that laypeople do not talk about mental states qua mental states, or the mind qua mind. Consequently, asking people whether they think of pains as located in the mind, so the objection goes, is too far removed from people's ordinary talk. However, it is important to note that we did not conduct a corpus-linguistic study on pain reports, testing people's use of certain terminology. Instead, we attempted to directly tap into people's conception of pain. People certainly understand the phrase in my mind' and hence are capable of evaluating the plausibility that pains are not in the body but in a person's mind. Moreover, if this objection were successful, we should expect a much greater number of participants to have chosen Option E in our first study- "None of the above: I don't agree with any of these statements." - but only a small minority did so. Similarly, we would expect a large percentage of participants to select the neutral response to the questions in our second study, but again this was not the case. For example, only $14 \%$ of the American participants and $10 \%$ of the South Korean participants gave the neutral response to the question asking whether the pain was located in the mind.

Second, a more promising version of this objection highlights the second of the two factors that we've discussed, noting that the semantics of pain reports is such that pains are located in body parts and not in the mind. It would then be argued that people didn't answer that the pain is located in the mind simply because this violates the semantics of ordinary pain reports, which they find hard to accept. Again, we do not find this objection convincing: advocates of the view that pains are thought to be mental states need to explain why pains are reported to be in body parts, even though they are

${ }^{42}$ See the second study in (Sytsma 2010a), however, for an exception. 
not really located there. Arguably, the most plausible account considers a statement like 'there is pain in my hand' as shorthand for 'I feel a pain that is caused by my hand.' If that were the case, however, then the participants in our study should not have located pains in bodily locations, because our scenario was specifically designed to make salient the independence of the phenomenological component and the bodily disorder.

Before we continue with an analysis of the cross-cultural part of this study, we would like to give an interpretation of people's "bodily" responses to the referred pain case. We were particularly interested in finding out whether people would identify pains with bodily disorders or give priority to the felt location of the pains. Our results do not strongly support either option, however, and overall they suggest that neither option is a clearly dominant factor in the ordinary conception of pain.

There are at least two possible explanations for this outcome. First, dissociations between bodily disorders and the phenomenology of feeling pain are rare and hard to evaluate. Thus, it is not unlikely that people felt uncertain about what to make of the referred pain scenario and either had no strong preference for either view or were sincerely torn between both options. Second, it might be argued that the bodily conception of pain is not unitary. According to this explanation, one group of people strongly identifies pains with bodily disorders, and considers the felt location of pain to be an overridable indication of where the bodily disorder has occurred, while a second group of people takes the felt location of pain to be paramount for purposes of determining the location of pain, with bodily disorders merely being causes of bodily pains.

While a more thorough investigation is called for, there are at least two reasons to expect that the bodily conception of pain is not unitary. First, as seen in the scatterplots in Figure 3, nearly half of the participants in our second study endorsed one of the two claims while denying the other $(51.6 \%$ of the Americans and $48.4 \%$ of the South Koreans). We also find that these participants were split with regard to which of the two claims they endorsed, with $52.1 \%$ of the Americans and $68.9 \%$ of the South Koreans endorsing the first claim. ${ }^{43}$

Second, after answering the forced-choice questions in Study 1, the American participants were asked to explain their answer choice. A qualitative analysis of these responses suggests several divergent lines of thought. With regard to the explanations given for locating the pain where the damage was,

${ }^{43}$ We should also mention, however, that a sizable minority of the participants either gave a neutral response to one or the other of the two claims or endorsed both claims (47.3\% of the Americans, $44.1 \%$ of the South Koreans), which offers some support for the first explanation given above. 
a substantial number of participants noted the plausibility of an appearancereality distinction for pain. Representative examples include that "pain from one area of the body may present itself in another area of the body" and that "the pain is not as it seems." The second most common explanation was to defer to the presumed expertise of the doctor. For example, participants wrote that "it can be proven that the pain is in Jack's liver by a trained medical professional," that "the doctor has experience and has also run tests to assure that the problem is indeed in Jack's liver, regardless of how Jack feels," and that "the Dr. has studied well and ran confirmation tests and has a better physiological understanding." It seems that for these and many other participants, the pain is located where the "problem" is, and that medical practioners are in the best position to determine the location of that problem.

With regard to the explanations given for locating the pain where it is felt to be, participants again frequently appealed to authority; this time it was not the physician's authority, however, but Jack's authority as the person feeling the pain. For instance, participants wrote "that's where he said his pain is and people know how they feel," "if Jack said its in his arm, its in the arm; only Jack knows what hurt him in his body," and "the important thing here is Jack's perspective." And other participants focused on the felt location of the pain without specifically noting Jack's authority: "his arm hurts regardless of the actual infection being in his liver," "Jack can still have pain in his left arm, even if the pain is the result of an infection in a different area of his body," "regardless of what is wrong with Jack internally, he still feels pain in his arm." Such explanations suggest that these participants hold that we should take the phenomenal aspect of pains at face value, even if the bodily disorder occurs at a different place.

While we prefer to refrain from drawing strong conclusions from these explanations, they are suggestive of the claim that there are multiple bodily conceptions of pain: whereas one group focuses on the location of the bodily disorder, the other seems to identify the location of the pain with where it is felt to be.

\subsection{Cultural effects on people's conception of pain}

In Section 2 we noted that investigating the conception of pain amongst South Koreans provides an interesting contrast to studies examining how Westerners think about pain. Specifically, we suggested that if people's views on the location and nature of pain are molded by cultural factors, then it is likely that there would be differences in this regard between South Koreans and Americans. However, we also expressed skepticism about finding any such differences. According to our own account, people's thinking about the location of pain is dominated by the phenomenology of feeling pain as well 
as the semantics of pain reports. Given the lack of any known differences in the felt and reported location of pains between Americans and South Koreans, we hypothesized that no difference would be found.

The results of our studies are in line with our hypothesis. Of course, a lack of evidence does not prove that cultural factors have no influence on the basic conception of pain. Nonetheless, given our positive results and the power of our studies, if such an effect exists it is likely to be small. Most importantly, across our studies a large majority of each group endorsed a bodily view, while only a small minority of either group endorsed a mental-state view. In regards to the two possible bodily locations our data is less clear. In Study 1, a marginally significant effect was found indicating that South Koreans more often locate pains where the bodily disorder is found. The results for our second study were more mixed, but the scatterplots shown in Figure 3 offer some additional support. We found that roughly half of each group endorsed one location claim while denying the other, with the Americans being roughly evenly split between the two camps, while the South Koreans were twice as likely to locate the pain where the disorder is found than where it is felt to be.

These results are consistent with the considerations we presented in Section 2, including both the tendency toward collectivist thinking present in South Korea and the phenomenon of Hwa-byung. Observable bodily disorders are undoubtedly physical realities and the possession of them does not constitute a loss of face within one's community. In contrast, the phenomenology of feeling pain is hidden and can be more readily suppressed, with it often being the case that feelings of pain are not talked about or are otherwise considered to be improper topics of discourse. As such, it would not be surprising if South Koreans focus more on the location of the bodily disorder compared to the phenomenology of feeling pain.

\subsection{Pains vs. sounds}

In addition to examining people's conception of pain, we investigated whether people take sounds to be (a) located at their source, (b) located where they are heard to be, or (c) located in the mind. The aim of this part of our studies was to examine whether the response profile regarding the location of pains mirrors the response profile of a typical sensory object like sound. The results indicate that people treat pains similarly to sounds in terms of taking them to be located outside of the mind. We also found an interesting difference in the respective response profiles, however. Whereas both Americans and South Koreans seemed to have been torn between locating pain at the source (liver) or the felt location (arm) of the pain, most 
Americans and most South Koreans located the sound at its source and not where it seemed to be coming from.

This observed discrepancy might be accounted for by what philosophers of pain have called the privacy of pains. Pains are considered private in the sense of being felt only by a single person. With regard to the ordinary conception of pain, however, empirical evidence indicates that this is not taken to be a necessary feature of pains, but merely contingent on the fact that people do not typically share their bodies (Sytsma 2010a). Even though the doctor is able to locate the bodily disorder in Jack's liver in our scenario, she is not able to feel Jack's pain. The privacy of pains also means that people are usually thought to be the ultimate authority with regards to their own pains. In contrast, the heard sound of the ambulance is not private to Jim, but can be heard by both Jim and the expert. Thus, the difference in results can be explained by the fact that many people hold Jack to be the authority over his pain: if he says he feels the pain in his arm, that's where the pain must be located. A similar strategy is not available for reasoning about sounds.

\section{Conclusion}

Philosophers have generally held that pain is a mental state and that this view reflects the ordinary conception of pain. If this is correct, then the obvious answer to the question 'Where is your pain?' is that it is in your mind. In this article we reported the results of two cross-cultural studies testing whether Americans and South Koreans give the response predicted by the philosophical orthodoxy. And we found that they do not: rather than conceiving of pains as mental states, the data suggest that both groups overwhelmingly conceive of pains as bodily states. Additionally, our studies reveal two further points of interest for further research on the ordinary conception of pain. First, despite there being notable cross-cultural differences between Americans and South Koreans that might be expected to influence how they understand pain, these differences seem to have at most a minor effect on their conceptions of pain. This supports our view that the cross-culturally universal aspects of felt and reported location shape people's conception of pain. Second, both Americans and South Koreans seem to be divided between thinking that pains should be identified with bodily disorders on the one hand, and thinking that pains are located where they feel their pains to be on the other hand. Thus, although we were able to provide a general answer to the question of where people take their pains to be-namely, they tend to locate pains in the body-additional work is needed for a full account of the ordinary conception of pain. 


\section{Acknowledgments}

Authors are listed alphabetically. We would like to thank Jonathan Livengood for his help with some of the stats in this article. We would also like to thank an anonymous reviewer for Studia Philosophica Estonica, Ramon Das, Nicky Drake, Simon Keller, Anton Killin, Don Locke, Anna Reuter, and Markus Werning for their helpful comments on earlier drafts of this article. This work was supported in part by a FHSS JRC Small Grant from Victoria University of Wellington and a National Research Foundation of Korea Grant funded by the Korean Government (NRF-2014S1A5B8063466).

\section{Bibliography}

Arendt-Nielsen, L. and Svensson, P. (2001). Referred muscle pain: Basic and clinical findings, The Clinical Journal of Pain 17: 11-19.

Arico, A., Fiala, B., Goldberg, R. and Nichols, S. (2011). The folk psychology of consciousness, Mind \& Language 26: 327-352.

Aydede, M. (2006). Introduction: A critical and quasi-historical essay on theories of pain, in M. Aydede (ed.), Pain: New Essays On Its Nature and the Methodology of Its Study, The MIT Press, Cambridge, MA, pp. 1-58.

Aydede, M. (2009). Pain, in E. N. Zalta (ed.), The Stanford Encyclopedia of Philosophy, Spring 2013 Edition.

URL: $h$ ttp://plato.stanford.edu/archives/spr2o13/entries/pain

Buckwalter, W. and Phelan, M. (2013). Function and feeling machines: A defense of the philosophical conception of subjective experience, Philosophical Studies 166: 349-361.

Callister, L. (2003). Cultural influences on pain perceptions and behaviors, Home Health Care Management \& Practice 15: 207-211.

Diller, A. (1980). Cross-cultural pain semantics, Pain 9: 9-26.

Fiala, B., Arico, A. and Nichols, S. (2014). You, robot, in E. Machery and E. O'Neill (eds), Current Controversies in Experimental Philosophy, Routledge, New York, pp. 31-47.

Fiebich, A. and Coltheart, M. (2015). Various ways to understand other minds: Towards a pluralistic approach to the explanation of social understanding, Mind and Language 30: 235-258.

Free, M. (2002). Cross-cultural conceptions of pain and pain control, Baylor University Medical Center Proceedings 15: 143-145. 
Hill, C. (2006). Ow! the paradox of pain, in M. Aydede (ed.), Pain: New Essays on Its Nature and the Methodology of Its Study, The MIT Press, Cambridge, MA, pp. 75-98.

Hofstede, G. (2011). Dimensionalizing cultures: The Hofstede model in context, Online Readings in Psychology and Culture 2: 1-26.

Huebner, B. (2010). Commonsense concepts of phenomenal consciousness: Does anyone care about functional zombies?, Phenomenology and the Cognitive Sciences 9: 133-155.

Inglehart, R. and Baker, W. E. (2000). Modernization, cultural change, and the persistence of traditional values, American Sociological Review 65: 1951.

Jack, A. and Robbins, P. (2012). The phenomenal stance revisited, Review of Philosophy and Psychology 3: 383-403.

Jackson, F. (1980). A note on physicalism and heat, Australasian Journal of Philosophy 58: 26-34.

Ketterer, H., Han, K. and Weed, N. C. (2010). Validation of Korean MMPI2 Hwa-byung scale using a Korean normative sample, Cultural Diversity and Ethnic Minority Psychology 16: 379-385.

Kim, J. W., Jung, I. C., Kang, H. W., Lee, S. G. and Chung, S. Y. (2013). Clinical guidelines for Hwabyung, The Korean Society of Oriental Neuropsychiatry. Hwabyung Research Center.

Knobe, J. and Prinz, J. (2008). Intuitions about consciousness: Experimental studies, Phenomenology and the Cognitive Sciences 7: 67-83.

Lee, J. H., Heo, N., Lu, J. and Portman, T. A. (2012). Qualitative exploration of acculturation and life-span issues of elderly Asian Americans, Adultspan Journal 12: 4-23.

Lin, K. M. (1983). Hwa-byung: A Korean culture-bound syndrome?, American Journal of Psychiatry 140: 105-107.

Machery, E. and Sytsma, J. (2011). Robot pains and corporate feelings, The Philosophers' Magazine 52: 78-82.

Markus, H. R. and Kitayama, S. (1991). Culture and the self: Implications for cognition, emotion, and motivation, Psychological Review 98: 224-253.

Martinez Mateo, M., Cabanis, M. and Krach, S. (2013). Difference and the self: Individualism and collectivism in cultural neuroscience, Frontiers in Human Neuroscience 3: 919. 
Mesquita, B. and Ellsworth, P. C. (2001). The role of culture in appraisal, in K. R. Scherer, A. Schorr and T. Johnstone (eds), Appraisal Processes in Emotion, Oxford University Press, Oxford, pp. 233-248.

Moore, R. and Brodsgaard, I. (1999). Cross-cultural investigations of pain, Task Force on Epidemiology of the International Association for the Study of Pain, International Association for the Study of Pain Press., Seattle, pp. 538 o.

Nagasako, E., Oaklander, A. and Dworkin, R. (2003). Congenital insensitivity to pain: An update, Pain 101: 213-219.

Nielsen, C., Staud, R. and Price, D. (2009). Individual differences in pain sensitivity: Measurement, causation, and consequences, The Journal of Pain 10: 231-237.

Nisbett, R., Choi, I., Peng, K. and Norenzayan, A. (2001). Culture and systems of thought: Holistic versus analytic cognition, Psychological Review 108: 291-310.

Park, J.-S., Park, S., Cheon, C.-H., Jang, B.-H., Lee, S.-H., Lee, S., Chung, S.-Y., Kim, J.-W., Jeon, C.-Y., Park, J.-H., Shin, J.-C. and Ko, S.-G. (2012). Effect of oriental medicine music therapy on patients with Hwa-byung: A study protocol for a randomized controlled trial, Trials 13: 161.

Park, Y. C. (2004). Hwabyung: Symptoms and diagnosis, Psychiatry Investigation 1: 25-28.

Phelan, M., Arico, A. and Nichols, S. (2013). Thinking things and feeling things: On an alleged discontinuity in the folk metaphysics of mind, Phenomenology and the Cognitive Sciences 12: 703-725.

Reuter, K. (2011). Distinguishing the appearance from the reality of pain, Journal of Consciousness Studies 18: 94-109.

Reuter, K. (2016). The developmental challenge to the paradox of pain, Erkenntnis Online First: 1-19.

Reuter, K., Phillips, D. and Sytsma, J. (2014). Hallucinating pain, in J. Sytsma (ed.), Advances in Experimental Philosophy of Mind, Bloomsbury, London, pp. 75-100.

Reuter, K. and Sytsma, J. (manuscript). Unfelt pain.

Reuter, K., Sytsma, J. and Werning, M. (manuscript). Experimentelle Philosophie des Schmerzes.

Schroll-Machl, S. (2008). Kulturstandards Ostasiens, in U.-H. Pradel, W. Süssenguth, J. Piontek and A. Schwolgin (eds), Praxishandbuch Logistik, Deutscher Wirtschaftsdienst, pp. 1-10. Abschnitt II.9.3. 
Schubert, K. and Klein, M. (2011). Das Politiklexikon: Liberalismus, Marxismus, Protestantismus, Bundeszentrale für politische Bildung, Dietz Verlag Bonn.

Sytsma, J. (2009). Phenomenological obviousness and the new science of consciousness, Philosophy of Science 76: 958-969.

Sytsma, J. (2010a). Dennett's theory of the folk theory of consciousness, Journal of Consciousness Studies 17: 107-130.

Sytsma, J. (2010b). Folk psychology and phenomenal consciousness, Philosophy Compass 5: 700-711.

Sytsma, J. (2012). Revisiting the valence account, Philosophical Topics 40: $179-198$.

Sytsma, J. (2014a). Attributions of consciousness, WIREs Cognitive Science 5: $635-648$.

Sytsma, J. (2014b). The robots of the dawn of experimental philosophy of mind, in E. Machery and E. O'Neill (eds), Current Controversies in Experimental Philosophy, Routledge, New York, pp. 48-64.

Sytsma, J. and Buckwalter, W. (eds) (2016). A Companion to Experimental Philosophy, Blackwell, Malden, MA.

Sytsma, J. (ed.) (2014c). Advances in Experimental Philosophy of Mind, Bloomsbury, London.

Sytsma, J. and Livengood, J. (2016). The New Experimental Philosophy: An Introduction and Guide, Broadview Press, Peterborough.

Sytsma, J. and Machery, E. (2009). How to study folk intuitions about consciousness, Philosophical Psychology 22: 21-35.

Sytsma, J. and Machery, E. (2010). Two conceptions of subjective experience, Philosophical Studies 151: 299-327.

Sytsma, J. and Machery, E. (2012). On the relevance of folk intuitions: A reply to Talbot, Consciousness and Cognition 21: 654-66o.

Talbot, B. (2012). The irrelevance of folk intuitions to the hard problem of consciousness, Consciousness and Cognition 21: 644-650.

Thomas, A. (2005). Kulturvergleichende Psychologie, 2. Auflage, Hogrefe, Göttingen.

Tye, M. (2006). Another look at representationalism about pain, in M. Aydede (ed.), Pain: New Essays on its Nature and the Methodology of its Study, The MIT Press, Cambridge, MA, pp. 99-120. 
Varnum, M., Grossmann, I., Kitayama, S. and Nisbett, R. (2010). The origin of cultural differences in cognition: The social orientation hypothesis, Current Directions in Psychological Science 1: 9-13.

Wierzbicka, A. (2014). "Pain" and "suffering" in cross-linguistic perspective, International Journal of Language and Culture 1: 149-173.

Xiaohong, W. and Qingyuan, L. (2013). The confucian value of harmony and its influence on Chinese social interaction, Cross-Cultural Communication 9: 6o-66.

\section{Appendix}

Referred pain vignette in Korean:

철수는 몸 상태가 안좋아서 병원에 오게 되었다.

의사가 철수에게 몸 상태를 설명해보라고 했을 때, 철수는 왼팔에 둔한 통증을 느낀다고 말했다. 노련한 의사는 철수의 내장들 중 하나가 감염되 었을 가능성을 즉각적으로 알아차렸다.

몇가지 검사를 해 본 후, 의사는 철수의 간이 감염되었다고 진단했다. 의 사는 철수에게 철수 그 자신이 어떻게 느끼던 간에, 왼쪽 팔에는 아무런 문제가 없고 진짜 문제가 있는 부분은 그의 간이라고 설명해주었다.

Question for Study 1:

다음의 다섯가지 선택지 중, 위의 철수의 사례를 잘 묘사하는 것을 골라주 세요.
A. 통증은 철수의 간에 있고, 철수는 단지 마치 그것이 그의 왼쪽 팔에 통증이 있는 것처럼 느낄 뿐이다.
B. 통증은 철수가 느끼는 바로 그 왼쪽 팔에 있다.
C. 통증은 철수의 마음에 있는 것이고, 그의 왼쪽 팔이나 간에 있는 것이 아니다.
D. 통증은 없다 - 철수의 간이나, 그의 왼쪽 팔, 혹은 그의 마음 어디 에도 없다.
E. 위의 답안 어느 것에도 동의하지 않는다. 


\section{Questions for Study 2:}

1. 통증은 철수의 간에 있고, 철수는 단지 마치 그것이 그의 왼쪽 팔에 통증이 있는 것처럼 느낄 뿐이다.

2. 통증은 철수가 느끼는 바로 그 왼쪽 팔에 있다.

3. 통증은 철수의 마음에 있는 것이고, 그의 왼쪽 팔이나 간에 있는 것이 아니다.

4. 통증은 없다-철수의 간이나, 그의 왼쪽 팔, 혹은 그의 마음 어디 에도 없다.

Referred sound vignette in Korean:

영희는 거리를 걸어내려가고 있었다. 이 때 마치 그의 왼쪽 어딘가에 병원 구급차 사이렌 소리가 들리는 것 같았다. 그러나, 영희가 왼쪽을 돌아보았 을 때, 거기에는 아무것도 없었다.

노련한 과학자는 영희의 옆에 서서 그의 행동을 잘 지켜보았다. 과학자는 병원 구급차가 아마도 영희의 오른쪽에 있었을 것이라고 즉각적으로 알 아차렸다. 주변을 둘러본 후, 과학자 병원 구급차가 영희의 오른쪽에 있는 주차장 안에 있다고 최종 결론내렸다.

과학자는 영희에게로 와서, 그 소리가 영희에게 어떻게 들렸든 간에 경보 기를 울리는 구급차는 사실은 영희의 오른쪽에 있다고 설명해주었다.

\section{Question for Study 1:}

다음의 다섯가지 선택지 중, 위의 영희의 사례를 잘 묘사하는 것을 골라주 세요.
A. 소리는 영희의 오른쪽에 있는 것이며, 그 소리는 마치 영희의 왼 쪽에 있는 것처럼 들릴 뿐이다.
B. 소리는 영희에게 들려왔던 바로 그 왼쪽에 있는 것이다.
C. 소리는 영희의 마음에 있는 것이지, 영희의 오른쪽이나 왼쪽에 있 는 것이 아니다.
D. 소리는 없다 - 영희의 왼쪽이나 오른쪽, 혹은 그의 마음 어디에도 없다.
E. 위의 답안 중 어느 것에도 동의하지 않는다. 


\section{Questions for Study 2:}

1. 소리는 영희의 오른쪽에 있는 것이며, 단지 그 소리는 마치 영희의 왼쪽에 있는 것처럼 들릴 뿐이다.

2. 소리는 영희에게 들려왔던 바로 그 왼쪽에 있다.

3. 소리는 영희의 마음에 있는 것이지, 영희의 오른쪽이나 왼쪽에 있 는 것이 아니다.

4. 소리는 없다-영희의 왼쪽이나 오른쪽, 혹은 그의 마음 어디에도 없다. 